\title{
Adubação com boro no crescimento de mudas de mogno-africano
}

\section{Matheus da Silva Araújo', Marcela Amaral de Melo², Bárbara Elias Reis Hodecker³, Vitor Corrêa de Mattos Barretto ${ }^{4}$, Ednaldo Cândido Rocha ${ }^{5}$}

\author{
${ }^{1}$ Universidade de Brasília, Campus Darcy Ribeiro, Brasília, Distrito Federal, Brasil. E-mail: matheusflorestal@outlook.com \\ ${ }^{2}$ Instituto Federal Goiano, Campus Urutaí, Urutaí, Goiás, Brasil. E-mail: marcela.ueg.eng.florestal@ outlook.com \\ ${ }^{3}$ União Pioneira de Integração Social (UPIS), Campus Lagoa Bonita, Brasília, Distrito Federal, Brasil. E-mail: beliasreis@gmail.com \\ ${ }^{4}$ Universidade Estadual Paulista, Campus de Dracena, Dracena, São Paulo, Brasil. E-mail: barretto@ dracena.unesp.br \\ ${ }^{5}$ Universidade Estadual de Goiás, Campus Ipameri, Ipameri, Goiás, Brasil. E-mail: ednaldorocha@ yahoo.com.br
}

Recebido: 27/10/2017; Aceito: 01/11/2017.

\section{RESUMO}

Em razão da escassez de informações sobre adubação em mogno-africano, no presente estudo, objetivou-se avaliar a adubação com boro (B) no crescimento inicial de mudas de mogno-africano (Khaya senegalensis A. Juss). O experimento foi realizado em estufa, em recipientes de plástico com capacidade de $7 \mathrm{dm}^{3}$ e utilizado como substrato solo Latossolo Vermelho-Amarelo distrófico. O delineamento experimental utilizado foi inteiramente casualizado, com cinco tratamentos e seis repetições. Os tratamentos foram constituídos de cinco doses de $\mathrm{B}\left(0 ; 0,5 ; 1,0 ; 2,0\right.$ e 4,0 $\left.\mathrm{mg} \mathrm{dm}^{-3}\right)$, utilizando-se o ácido bórico como fonte. Aos 150 dias após o transplantio foram analisados a altura da planta, o diâmetro do coleto, o número de folíolos e a matéria seca de folhas, caule e raiz. As plantas submetidas às menores doses de $\mathrm{B}\left(0 \mathrm{a} 1 \mathrm{mg} \mathrm{dm}^{-3}\right)$ apresentaram os maiores índices de crescimento para todas as variáveis analisadas. Por outro lado, as maiores doses de B utilizadas ( 2 e 4 $\mathrm{mg} \mathrm{dm}^{-3}$ ) afetaram negativamente o desenvolvimento das plantas, indicando fitotoxidade desse micronutriente quando utilizado em doses elevadas. Assim, para o crescimento inicial de mudas de mogno-africano na condição estudada, em que o substrato contenha teores de B de cerca de $0,19 \mathrm{mg} \mathrm{dm}^{-3}$, não é necessária a aplicação de boro via fertilizantes.

Palavras-chave: espécie nobre; nutrição florestal; silvicultura.

\section{Fertilization with boron on the initial growth of african-mahogany seedlings}

\begin{abstract}
Due to the scarcity of information about fertilization in primed structural steel, in the present study, it was aimed to evaluate a fertilizing with boron (B) no initial growth of seedlings of primed structural steel (Khaya senegalensis A. Juss). The experiment was carried out in the greenhouse, in plastic containers with a capacity of 7 $\mathrm{dm}^{3}$ and substrate was used an Latossolo Vermelho-Amarelo. The experimental design was completely randomized design, with five treatments and six replications. The treatments were comprised of five doses of $\mathrm{B}$ $\left(0 ; 0.5 ; 1.0 ; 2.0\right.$ and $\left.4.0 \mathrm{mg} \mathrm{dm}^{-3}\right)$, languages-if boric acid as a source. To 150 days after transplanting, plant height, collar diameter, number of leaves and dry weight of leaves, stem and root were measured. As plants subject to smaller rates of $\mathrm{B}\left(0\right.$ to $\left.1 \mathrm{mg} \mathrm{dm}^{-3}\right)$ showed the largest growth impact for all variables analyzed. On the other hand, as higher doses of B used $\left(2\right.$ and $\left.4 \mathrm{mg} \mathrm{dm}^{-3}\right)$ negatively affected the development of plants, indicating that when micronutrient phytotoxicity notes in high doses. So, for the initial development of seedlings of African primed structural steel in the condition studied in the substrate contains B levels of about $0.19 \mathrm{mg} \mathrm{dm}^{-3}$, does not require an application of boron through fertilizer
\end{abstract}

Key words: noble species; forest nutrition; forestry 


\section{Introdução}

Khaya senegalensis A. Juss, conhecido como mogno-africano, é originário da África, onde ocorre principalmente em florestas ciliares e savanas florestadas com alta precipitação. É uma espécie heliófila, podendo atingir até $35 \mathrm{~m}$ de altura em solos férteis, diâmetro de até $1,5 \mathrm{~m}$ e de 8 a $16 \mathrm{~m}$ de fuste sem ramificações laterais. Constitui-se em uma espécie ideal para plantio em regiões com índices pluviométricos compreendidos entre 800 a $1600 \mathrm{~mm}$ de chuvas por ano, respondendo bem à irrigação. A madeira é dura, pesada, durável e possui desenhos de grande beleza, o que justifica seu uso na fabricação de mobiliário, bem como na decoração de interiores (PINHEIRO et al., 2011).

Dentre as principais atividades que objetivam elevar a produtividade dos sítios florestais, destacam-se os estudos direcionados ao manejo do solo, principalmente aqueles relacionados à adubação das culturas. Contudo, cabe ressaltar que ainda não existem informações exatas sobre o desenvolvimento e exigências mínimas para a maximização desta produtividade. As quantidades de adubos aplicados dependerão das necessidades nutricionais da espécie utilizada, da fertilidade do solo, da forma de reação dos adubos com o solo, da eficiência dos adubos, de fatores de ordem econômica e da disponibilidade hídrica local (RYAN et al., 2010).

A fertilização florestal, principalmente no estágio de produção de mudas, geralmente é realizada de modo empírico e utilizando-se de única formulação de macronutrientes (nitrogênio, fósforo e potássio), independente do tipo de solo, da espécie e da época de plantio (BARROS; NOVAIS, 1990). É importante ressaltar que a fertilidade dos solos, a nutrição e adubação são componentes essenciais para a construção de um sistema de produção eficiente. Além disso, mudas saudáveis apresentam maior desenvolvimento de parte aérea e sistema radicular, garantindo assim maior eficiência e resistência à condições adversas quando submetidas a campo.

Apesar da existência de poucos trabalhos relacionados à adubação com macronutrientes na cultura do mogno-africano (PEREZ et al., 2016; SMIDERLE, 2016; CORCIOLI et al., 2016), quando se trata da adubação com micronutrientes, as informações são ainda mais escassas. Mesmo requeridos em pequenas quantidades, os micronutrientes são de grande importância para o desenvolvimento de uma planta, estes estão presentes nas principais funções metabólicas dentro das células e sua falta pode acarretar grandes perdas na produtividade (CORCIOLI et al., 2016).

De acordo com Malavolta (1980), o boro (B), juntamente com o zinco $(\mathrm{Zn})$, são os micronutrientes que se mostram mais deficientes nos solos brasileiros. Atualmente, vários estudos têm focado no entendimento dos reflexos da nutrição com boro no desenvolvimento das espécies florestais. O boro possui importante papel na estruturação da parede celular, por participar ativamente da formação dos ramnogalacturonanos II (O’NEILL et al., 2004), constituinte da pectina celular. Adicionalmente, possui crucial papel na formação de novos tecidos, crescimento radicular e também na produtividade, além de possuir relativa mobilidade floemática em algumas espécies florestais (SIEBENEICHLER et al., 2005; MATTIELLO et al., 2009a; HODECKER et al., 2014).

A dosagem adequada de $\mathrm{B}$ a ser fornecida às plantas é muito relativa; uma das maiores preocupações nas adubações em função da estreita relação entre o nível adequado e o tóxico do micronutriente. Cabe ressaltar que a dose ótima de $\mathrm{B}$ para determinada espécie pode promover o retardo do crescimento de outras (REIS et al., 2012; BRIGHENTI; MULLER, 2014).

Barreto et al. (2007), estudando o crescimento de clones de eucalipto sob doses de B cultivados em vasos, constataram incremento no crescimento em altura e diâmetro das plantas com a adição de B. Mattielo et al. (2009a), avaliaram a mobilidade do B em dois clones de eucalipto, concluindo que a translocação de $\mathrm{B}$ é maior em plantas deficientes do nutriente. Tirlone et al. (2011), avaliando o crescimento de Corymbia citriodora (Hook.) K.D.Hill \& L.A.S.Johnson sob aplicação de boro constatou que não houve diferenças em altura e diâmetro das plantas submetidas a doses crescentes de B ( $0 ; 0,2 ; 0,4 ; 0,6$ e $0,8 \mathrm{~g} /$ planta de boro) cultivados no período de seca.

Em decorrência disso, fundamenta-se a importância da realização de estudos envolvendo diferentes doses de adubação com B no desenvolvimento inicial de plantas de mogno-africano, visando à obtenção de mudas de boa qualidade e, consequentemente, maior sobrevivência pós-plantio, obtendo maior produtividade e sustentabilidade na produção florestal, por meio de sua adequada recomendação nutricional. Cabe ressaltar que na literatura não há trabalhos semelhantes para a espécie utilizada. Diante do exposto, objetivou-se, com o presente estudo, avaliar a adubação com boro (B) no crescimento inicial de plantas de mogno-africano.

\section{Material e Métodos}

O experimento foi conduzido em estufa, na área experimental da Universidade Estadual de Goiás, Câmpus Ipameri (coordenadas geográficas $17^{\circ} 43^{\prime} 19^{\prime}$ ' latitude S e $48^{\circ} 09^{\prime} 35^{\prime}$ " longitude $\mathrm{W}$ e altitude de 764 m). As características da estufa utilizada são: $3,5 \mathrm{~m}$ de pé direito, 30,0 $\mathrm{m}$ comprimento, 7,0 $\mathrm{m}$ de largura, fechada nas laterais com sombrite $50 \%$ na cor preta e cobertura com plástico transparente 150 micras. O Município de Ipameri está localizado na região sudeste do Estado de Goiás, onde o clima é classificado como 
Aw (tropical estacional) com precipitação anual de aproximadamente $1600 \mathrm{~mm}$, sendo caracterizada por duas estações bem definidas, uma seca no inverno e uma chuvosa no verão, e com temperatura média de cerca de $23{ }^{\circ} \mathrm{C}$ (ALVARES et al., 2013). As temperaturas dentro da estufa variaram entre $11{ }^{\circ} \mathrm{C}$ (mínima) e $43{ }^{\circ} \mathrm{C}$ (máxima) com média de $27^{\circ} \mathrm{C}$.

$\mathrm{O}$ substrato utilizado foi um solo agrícola classificado como Latossolo Vermelho-Amarelo distrófico, coletado na camada subsuperficial $(0,20$ a $0,40 \mathrm{~m})$. Na análise físico-química, o substrato apresentou os seguintes valores iniciais: 300, 80,0 e $620,0 \mathrm{~g} \mathrm{~kg}^{-1}$ de argila, silte e areia, respectivamente; $\mathrm{pH}$ $\left(\mathrm{CaCl}_{2}\right)=5,1 ; \mathrm{H}+\mathrm{Al}=2,2 \mathrm{cmol}_{\mathrm{c}} \mathrm{dm}^{-3} ; \mathrm{Ca}=0,8$ $\mathrm{cmol}_{\mathrm{c}} \mathrm{dm}^{-3} ; \mathrm{Mg}=0,3 \mathrm{cmol}_{\mathrm{c}} \mathrm{dm}^{-3} ; \mathrm{P}($ Mehlich-1) $=1,2$ $\mathrm{mg} \mathrm{dm}{ }^{-3} ; \mathrm{K}=0,04 \mathrm{cmol}_{\mathrm{c}} \mathrm{dm}^{-3} ;$ Matéria orgânica $=9,0 \mathrm{~g}$ $\mathrm{dm}^{-3} ; \mathrm{CTC}=3,36 \mathrm{cmol}_{\mathrm{c}} \mathrm{dm}^{-3} ; \mathrm{V} \%=34,57 ; \mathrm{Cu}=1,9 \mathrm{mg}$ $\mathrm{dm}^{-3}, \mathrm{Fe}=43,9 \mathrm{mg} \mathrm{dm}^{-3}, \mathrm{Mn}=3,4 \mathrm{mg} \mathrm{dm}^{-3}, \mathrm{Zn}=0,2$ $\mathrm{mg} \mathrm{dm}^{-3}, \mathrm{~B}=0,19 \mathrm{mg} \mathrm{dm}^{-3}$, respectivamente.

A espécie utilizada foi o $K$. senegalensis A. Juss, propagada por meio de sementes importadas do Continente Africano, em tubetes com capacidade de 53 $\mathrm{cm}^{3}$, preenchidos com substrato comercial. Nesse período não houve adubação mineral e permaneceram até a data de plantio nos tratamentos propostos. $\mathrm{Na}$ época do transplantio, as mudas tinham a altura média de $15 \mathrm{~cm}$ e o diâmetro do coleto em média de $8 \mathrm{~mm}$.

$\mathrm{O}$ delineamento experimental utilizado foi $\mathrm{o}$ inteiramente casualizado, com cinco tratamentos e seis repetições cada, totalizando 30 unidades experimentais, sendo representado por um vaso com uma planta. Os tratamentos constituíram-se de cinco doses de boro ( $\mathrm{B}=$ $0 ; 0,5 ; 1,0 ; 2,0$ e $4,0 \mathrm{mg} \mathrm{dm}^{-3}$ ), a fonte de adubação utilizada foi o ácido bórico.

Em função da análise físico-química do solo utilizado, para elevar a saturação por bases do solo para $60 \%$, todos os tratamentos receberam calagem. O calcário foi aplicado individualmente em cada vaso e encubado por um período de 45 dias antecedendo a instalação do experimento. Após o período de encubação foi realizada a adubação com nitrogênio (80 $\mathrm{mg} \mathrm{dm}^{-3}$ ), fósforo $\left(150 \mathrm{mg} \mathrm{dm}^{-3}\right.$ ) e potássio $\left(80 \mathrm{mg} \mathrm{dm}^{-}\right.$ ${ }^{3}$ ), incorporando as doses individualmente em cada vaso. Em seguida foi aplicada através de solução nutritiva doses dos micronutrientes: manganês $(1,5 \mathrm{mg}$ $\left.\mathrm{dm}^{-3}\right)$, zinco $\left(5 \mathrm{mg} \mathrm{dm}^{-3}\right)$, cobre $\left(0,5 \mathrm{mg} \mathrm{dm}^{-3}\right)$ e molibdênio (0,1 $\mathrm{mg} \mathrm{dm}^{-3}$ ) (CIRIELLO et al., 2014). As fontes utilizadas para calagem e adubação foram: calcário dolomítico PRNT 92\%, ureia, superfosfato triplo, cloreto de potássio, sulfato de manganês, sulfato de zinco, sulfato de cobre e molibdato de sódio, respectivamente. As doses dos nutrientes estabelecidos foram aplicadas individualmente em vasos de plástico com capacidade de $7 \mathrm{dm}^{3}$, com 5 orifícios de drenagem no fundo.
As mudas foram transplantadas para os vasos aos 120 dias de idade, no mês de outubro de 2015. A umidade do solo foi mantida durante todo o período experimental em aproximadamente $60 \%$ da capacidade máxima de retenção de água do solo. $\mathrm{O}$ volume de água evapotranspirada foi reposta, diariamente, por meio de pesagem dos vasos, irrigadas com água destilada.

Após 150 dias após o transplantio das mudas, as características de crescimento foram avaliadas, por meio da medição de altura de plantas, desde o colo até o ápice, com o auxílio de régua graduada em mm, diâmetro do coleto, utilizando-se de um paquímetro digital e número de folíolos, por meio de contagem manual.

Em seguida as plantas foram separadas em folhas, caule e raízes para a determinação de matéria seca. Realizou-se lavagem das partes das plantas com água destilada e, posteriormente, as mesmas foram colocadas em estufa de circulação forçada de ar por 72 horas, na temperatura de $70{ }^{\circ} \mathrm{C}$, até a obtenção de massa constante. Depois de secas, foram pesadas em balança analítica com precisão de $0,01 \mathrm{~g}$ para determinação da matéria seca de folhas, caule e raiz.

Com os dados obtidos, foi realizada a análise de componentes principais (PCA), adotando o critério de broken-stick para indicar o número de eixos usados na ordenação, foram então inseridas no gráfico as variáveis que apresentaram coeficientes de correlação com os eixos superiores a 0,6, em valores absolutos. Para verificar se houve diferença entre os tratamentos, foi aplicada a análise de variância multivariada por permutação - PERMANOVA (ANDERSON, 2001). Previamente à realização dessas análises os dados foram padronizados e foram adotadas as distâncias Euclidianas como medidas de afastamento entre as amostras. Além disto, foi utilizada a análise de regressão simples para avaliar a influência das doses de B em cada variável.

As análises estatísticas foram conduzidas utilizando os softwares SISVAR 5.4 (FERREIRA, 2011) e R versão 3.2 (R DEVELOPMENT CORE TEAM, 2015), utilizando o pacote vegan (OKSANEN et al., 2016).

\section{Resultados e Discussão}

Para as variáveis analisadas (altura, diâmetro do coleto, número de folíolos e matéria seca de folhas, caule e raiz) o resultado da PERMANOVA mostra que houve diferença significativa (Pseudo $\mathrm{F}=18,63$; $\mathrm{p}=$ 0,$001 ; R^{2}=0,75$ ) entre os tratamentos (Figura 1).

A análise de componentes principais (PCA) evidenciou a formação de três grupos distintos de amostras; o primeiro deles foi formado pelas amostras provenientes de plantas que receberam as menores doses de B (0 a $1 \mathrm{mg} \mathrm{dm}^{-3}$ ), as quais apresentaram os maiores valores para todas as variáveis analisadas. 


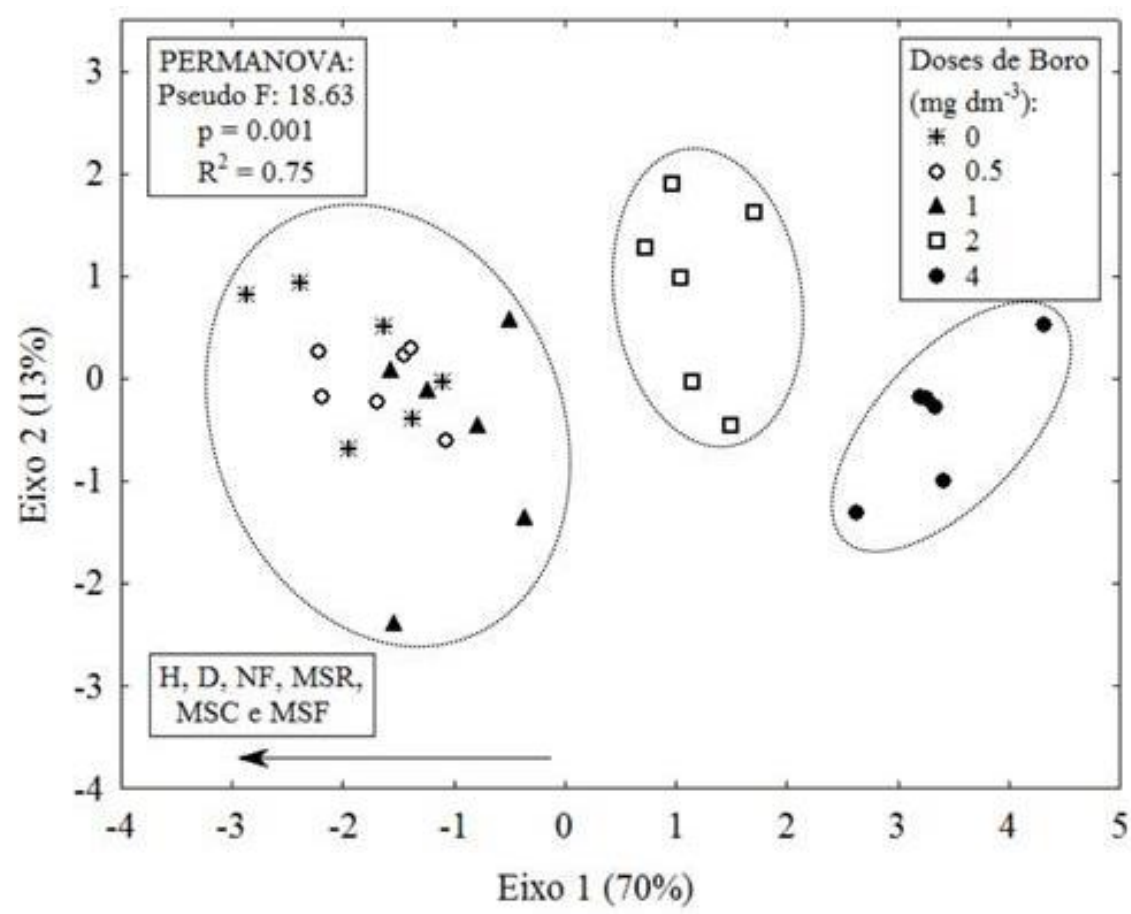

Figura 1. Resultado da análise de componentes principais (PCA) e da análise de variância multivariada por permutação (PEMANOVA) para as variáveis altura (H), diâmetro do coleto (D), número de folíolos (NF) e matéria seca de raiz (MSR), caule (MSC) e folhas (MSF) de plantas de mogno-africano adubadas com diferentes doses de boro, aos 150 dias.

O segundo grupo foi estruturado pelas amostras que

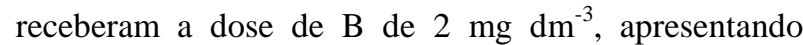
valores intermediários para as variáveis analisadas; e o terceiro grupo foi formado pelas amostras de plantas submetidas às maiores doses de $\mathrm{B}\left(4 \mathrm{mg} \mathrm{dm}^{-3}\right)$, as quais apresentaram os menores valores para as variáveis de crescimento estudadas (Figura 1).

Todas as variáveis analisadas apresentaram ajuste significativo $(\mathrm{p}<0,01)$ ao modelo de regressão linear decrescente (Figura 2), indicando que o aumento nas doses de $\mathrm{B}$ afetaram negativamente o desenvolvimento das plantas. Para variável altura, o maior valor foi obtido nas plantas de mogno-africano submetidas à dose $0 \mathrm{mg} \mathrm{dm}^{-3}$ cuja média foi de $72 \mathrm{~cm}$ planta $^{-1}$, valor 32,6 $\%$ maior que o observado $(54,3 \mathrm{~cm})$ nas plantas submetidas à dose $4,0 \mathrm{mg} \mathrm{dm}^{-3}$ (Figura $2 \mathrm{~A}$ ). O diâmetro médio do coleto das plantas submetidas à dose de $0 \mathrm{mg}$ $\mathrm{dm}^{-3}$ de B foi de $21,4 \mathrm{~mm}$ planta $^{-1}$, sendo $16,0 \%$ superior ao encontrado nas plantas submetidas a dose 4,0 $\mathrm{mg} \mathrm{dm}^{-3}$ (Figura 2B). Para o número de folíolos, nota-se que em média há maior produção de folíolos nas plantas submetidas à dose de $0 \mathrm{mg} \mathrm{dm}^{-3}$ (192 folíolos planta $\left.^{-1}\right)$, reduzindo sua produção com a elevação das doses (Figura 2C).

De maneira geral, as plantas de mogno-africano da testemunha ( $\left.0 \mathrm{mg} \mathrm{dm}^{-3} \mathrm{de} \mathrm{B}\right)$, apresentaram os maiores incrementos em altura, diâmetro do coleto, número de folíolos e matéria seca de raiz, caule e folhas, entretanto, com o aumento das doses houve uma diminuição em todas as variáveis analisadas. Sabe-se que a adubação com boro aumenta o crescimento e a produção das plantas e sua deficiência resulta numa rápida inibição do crescimento, pois o B possui papel fundamental no metabolismo e translocação de carboidratos, transporte de açúcares através das membranas, síntese de ácidos nucléicos e de fito-hormônios; formação de paredes celulares e divisão celular (GUPTA et al., 1985). No entanto, com base no teor de B no solo $\left(0,19 \mathrm{mg} \mathrm{dm}^{-3}\right)$, considerando o limite entre a deficiência e a toxidez, pode-se aferir que a espécie estudada é pouco exigente ao nutriente em fase inicial de crescimento, sendo sensível a doses elevadas do mesmo.

Assim como os resultados encontrados nas variáveis altura e diâmetro de coleto nas plantas de mognoafricano, analisando o crescimento inicial de plantas de cedro-australiano (Toona ciliata M. Roemer) sob doses de B e Zn em solução nutritiva, Carmo et al. (2010) concluíram que todos os parâmetros de crescimento e de qualidade das mudas foram afetados pelas doses crescentes de B. No entanto, as plantas de cedroaustraliano apresentaram respostas positivas as doses de $\mathrm{B}$, ao contrário das plantas de mogno-africano, fato que pode estar relacionado com a tolerância específica de cada espécie ao nutriente $\mathrm{B}$.

Adicionalmente, Mattiello et al. (2009b) afirmam que a resposta do eucalipto ao B depende da espécie, havendo diferenças entre elas na tolerância à deficiência e toxidez e na eficiência de utilização de B. No entanto, em copaíba, Duboc et al. (1996a) constataram que as plantas mostraram-se indiferentes à omissão de boro, provavelmente por sua deficiência estar relacionada à períodos com restrição hídrica. É importante ressaltar 
que algumas espécies apresentam alta sensibilidade à deficiência de B, enquanto outras são tolerantes. Nesse caso deve-se atentar especificadamente na exigência e tolerância de cada espécie e na época de aplicação deste micronutriente.

As plantas de mogno-africano submetidas à dose 0 $\mathrm{mg} \mathrm{dm}{ }^{-3}$ de B emitiram mais folhas quando comparadas às demais plantas (Figura 2C). Plantas nutridas adequadamente propiciam um ritmo mais acelerado de emissão de folhas, o que favorece a transpiração e alguns processos metabólicos como fotossíntese e condução de nutrientes, possibilitando maior desenvolvimento para a planta, desde que não submetida à stress hídrico (BERNARDINO et al., 2005).
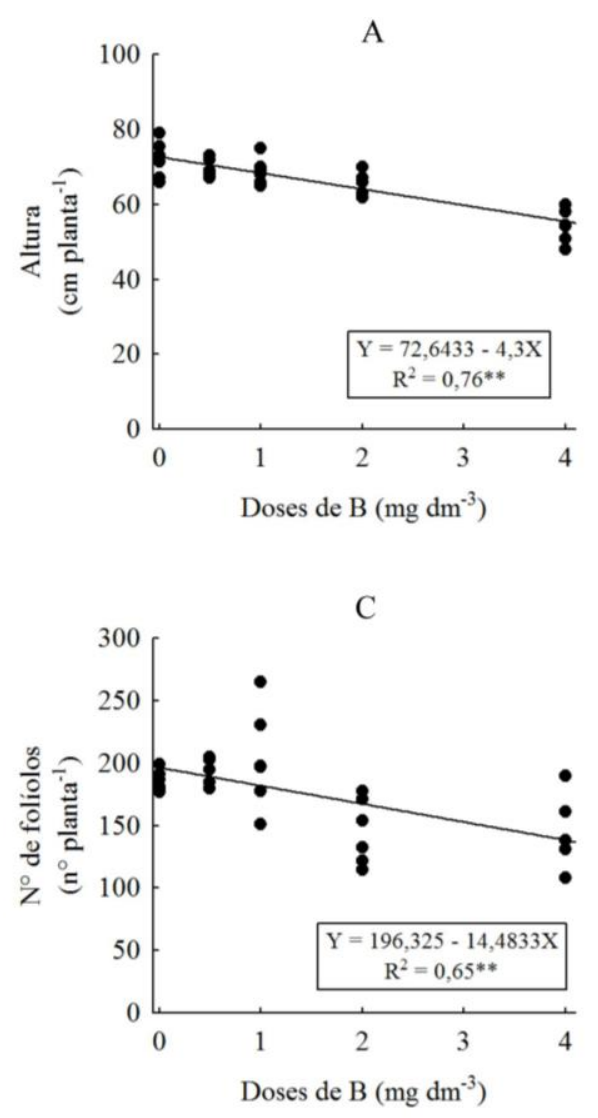

E

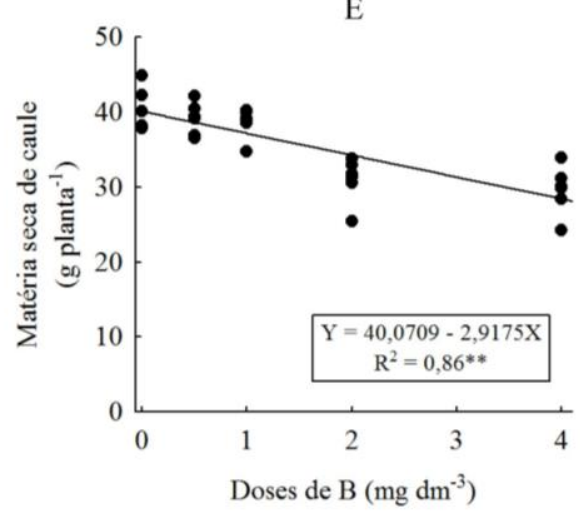

É preciso salientar que, segundo Malavolta (1980), o limite entre a concentração suficiente e a toxidez nutricional é muito estreito. Malavolta (1980) e Oliveira et al. (1982) relatam os sintomas prejudiciais causados à parte aérea e à raiz induzidos pela deficiência e toxidez de boro tal como foi observado no presente trabalho.

Em relação à matéria seca das partes das plantas, a maior produção de matéria seca de folhas, de caule e de raiz foi verificada nas plantas submetidas à dose $0 \mathrm{mg}$ $\mathrm{dm}^{-3}$, atingindo médias de 34,8, 40,2 e 45,7 $\mathrm{g} \mathrm{planta}^{-1}$, respectivamente. Estes valores são $57,7 \%, 35,8 \%$ e $172,8 \%$, respectivamente, superiores aos encontrados em plantas submetidas à dose de $4,0 \mathrm{mg} \mathrm{dm}^{-3}$ (Figura 2 $\mathrm{D}, \mathrm{E}, \mathrm{F})$.

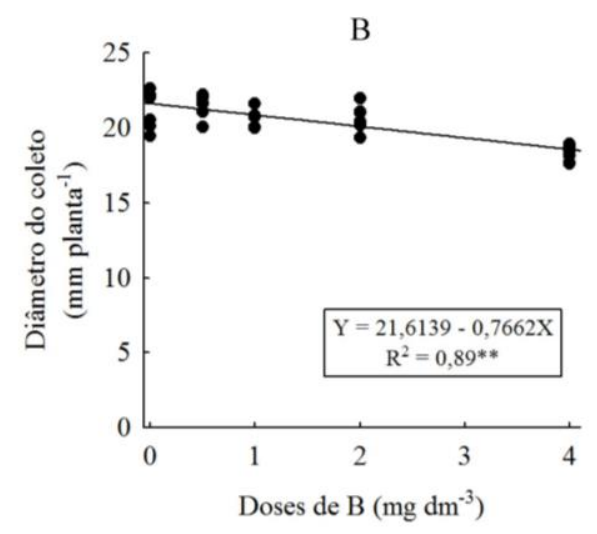

D
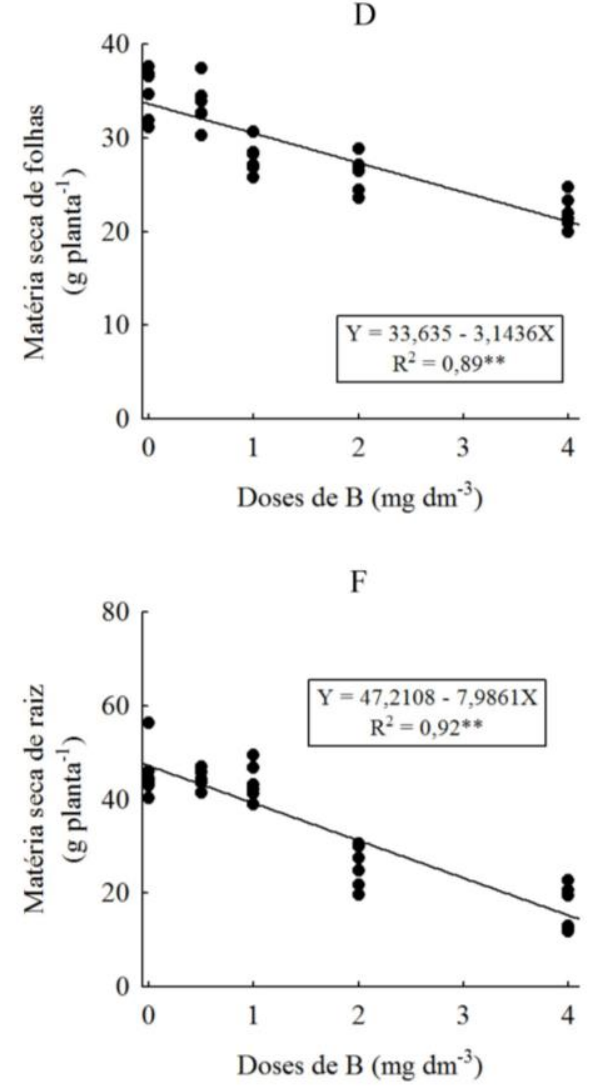

Figura 2. Funções de regressão para altura (A), diâmetro do coleto (B), número folíolos (C) e matéria seca de folhas (D), caule (E) e raiz $(\mathrm{F})$ de plantas de mogno-africano adubadas com diferentes doses de boro, aos 150 dias. ** significativo à $1 \%$ de probabilidade. 
Em avaliação do comportamento de mudas de cedroaustraliano (Toona ciliata M. Roemer), Carmo et al. (2010) concluíram que a ausência de boro limita a produção de matéria seca de folhas. No presente estudo a maior produção de matéria seca de folhas foi encontrada à dose $0 \mathrm{mg} \mathrm{dm}^{-3}$ de $\mathrm{B}$. Isto pode ter ocorrido em virtude da rápida mineralização da matéria orgânica presente no solo em função do calor retido na estufa nas épocas quentes, e, ou, teor suficiente deste elemento para as necessidades nutricionais da espécie em sua fase inicial de crescimento (CONCEIÇÃO et al., 2005).

De forma similar ao encontrado no presente estudo, em jatobá, Duboc et al. (1996b) encontraram menor produção de matéria seca de raiz, evidenciando também um possível efeito tóxico do boro para estas culturas, quando utilizado em concentração elevadas ( $>2 \mathrm{mg} \mathrm{dm}^{-}$ ${ }^{3}$ ). O boro é exigido em pequena quantidade pelas plantas de mogno-africano, contudo, ele está é de fundamental importância, diretamente relacionado com o desenvolvimento das gemas e das extremidades das raízes. Em caso de deficiência, tanto as novas brotações como o crescimento de novas raízes são paralisados, diminuindo a produção de biomassa.

O teor de B presente no substrato utilizado nesse estudo foi suficiente para o desenvolvimento inicial das plantas de mogno-africano, visto que as plantas submetidas à omissão de $\mathrm{B}$ via adubação apresentaram os maiores índices de crescimento em todas as variáveis analisadas. O substrato utilizado continha $0,19 \mathrm{mg} \mathrm{dm}^{-3}$ de B, valor considerado baixo para a cultura do eucalipto, no entanto, mostrou-se ideal para o crescimento inicial das plantas de mogno-africano, uma vez que as plantas não apresentaram sintomas de deficiência e toxidez quando submetidas a dose $0 \mathrm{mg}$ $\mathrm{dm}^{-3}$. Brighenti e Muller (2014), também trabalhando com Latossolo Vermelho-Amarelo com 0,17 e 0,19 mg $\mathrm{dm}^{-3} \mathrm{de}$ B no cultivo de mogno-africano em sistema silvipastoril, afirmaram que as plantas não apresentaram efeito significativo com a adição de B no teor de clorofila (índice SPAD). Tal fato pode estar relacionado à baixa exigência da espécie ao nutriente.

Durante todo o período do experimento houve controle na irrigação mantendo a capacidade de retenção de água no solo a $60 \%$, condição que facilita a absorção de $\mathrm{B}$, visto que este é absorvido via fluxo transpiracional (MATTIELLO et al., 2009a), ou seja, a presença de altas temperaturas encontradas em estufa, aliado ao elevado teor de água disponível no substrato, proporciona condições ideais para a transpiração vegetal potencializando a absorção do elemento. Desta maneira, ao elevar os teores de B do substrato, há toxidez do elemento, devido ao restrito limite entre adequado e tóxico encontrado para os micronutrientes.
Ademais é importante salientar que as plantas de mogno-africano, submetidas à dose $0 \mathrm{mg} \mathrm{dm}^{-3} \mathrm{de} \mathrm{B}$, não apresentaram sintomas de deficiência comumente observados como: folhas novas com clorose, murcha, queda das folhas, seguida da morte da gema apical (LIMA et al., 2003). Neste caso as condições iniciais do substrato utilizado foram suficientes para o desenvolvimento inicial da espécie em relação ao suprimento de B

\section{Conclusões}

As plantas de mogno-africano (K. senegalensis A. Juss) não responderam positivamente às doses crescentes de $\mathrm{B}$ nas fases iniciais de crescimento, não sendo necessária a aplicação do mesmo via fertilizantes quando utilizado o substrato com teores de $0,19 \mathrm{mg} \mathrm{dm}^{-}$ 3 de B.

O mogno-africano ( $K$. senegalensis A. Juss) é sensível à doses elevadas de $\mathrm{B} \quad\left(>2 \mathrm{mg} \mathrm{dm}^{-3}\right)$, apresentando redução no crescimento do sistema radicular e da parte aérea.

\section{Agradecimentos}

Agradecemos à Universidade Estadual de Goiás pela bolsa de incentivo ao pesquisador (PROBIP/PrP 009/2016) concedida a ECR.

\section{Referências Bibliográficas}

ALVARES, C. A.; STAPE, J. L.; SENTELHAS, P. C.; GONÇALVES, M. L. M.; SPAROVEK, G. Köppen's climate classification map for Brazil. Meteorologische Zeitschrift, Stuttgart, v. 22, n. 6, p. 711-728, 2013.

ANDERSON, M. J. A new method for non-parametric multivariate analysis of variance. Austral Ecology, Singapore, v. 26, n. 10 , p. $32-46,2001$

BARRETTO, V. C. M.; VALERI, S. V.; SILVEIRA, R. L. V. A.; TAKAHASHI, E. N. Eficiência de uso de boro no crescimento de clones de eucalipto em vasos. Scientia Forestalis, Piracicaba-SP, v. 1, n. 76, p. 21-33, 2007.

BARROS, N. F; NOVAIS, R. F. Relação solo-eucalipto. Viçosa, MG: Folha de Viçosa, 1990. 330 p.

BERNARDINO, D. C. S.; PAIVA, H. N.; NEVES, J. C. L.; GOMES, J. M.; MARQUES, V. B. M. Crescimento e qualidade de mudas de Anadenanthera macrocarpa (Benth.) Brenan em resposta à saturação por bases do substrato. Revista Árvore, Viçosa-MG, v. 29, n. 6, p. 863-870, 2005.

BRIGHENTI, A. M.; MULLER, M. D. Controle do capimbraquiária associado à nutrição com boro no cultivo do mogno-africano em sistema silvipastoril. Revista Ciência Agronômica, Fortaleza-CE v. 45, n. 4, p. 745-751, 2014. 
CARMO, D. L.; SILVA, B. V. N.; DIAS, J. S.; CARVALHO, J. G.; PINHO, P. J.; Crescimento de cedro-australiano sob doses de boro e zinco em solução nutritiva. Enciclopédia Biosfera, Goiânia-GO, v. 6, n. 11, p. 1-13, 2010.

CIRIELLO, V.; GUERRINI, I. A.; BACKES, C. Doses de nitrogênio no crescimento inicial e nutrição de plantas de guanandi. Cerne, Lavras-MG, v. 20 n. 4, p. 653-660, 2014.

CONCEIÇÃO, P. C.; AMADO, T. J.; MIELNICZUK, J.; SPAGNOLLO, E. Qualidade do solo em sistemas de manejo avaliada pela dinâmica da matéria orgânica e atributos relacionados. Revista Brasileira Ciência do Solo. ViçosaMG, v. 29 n. 5, p. 779-787, 2005.

CORCIOLI, G.; BORGES, J. D.; JESUS, R. P.; Deficiência de macro e micronutrientes em mudas maduras de Khaya ivorensis estudadas em viveiro. Cerne, Lavras-MG, v. 22 n. 1 p. 121-128, 2016.

DUBOC, E.; NELSON, V.; DAVIDE, A. C.; Fertilização de plântulas de Copaifera langsdorffii Desf. (Óleo Copaíba). Cerne, Lavras-MG, v. 2, n. 2, p. 31-47, 1996a.

DUBOC, E.; VENTURIM, N.; VALE, F. R.; DAVIDE, A. C.; Nutrição do jatobá (Hymenaea courbaril L. var. Stilbocarpa (Hayne) Lee et Lang). Cerne, Lavras-MG, v. 2, n. 1, p. 138$152,1996 b$.

FERREIRA, D. F. Sisvar: a computer statistical analysis system. Ciência e Agrotecnologia. Lavras-MG, v. 35, n. 6, p. 1039-1042, 2011.

GUPTA, U. C.; JAMES, Y. W.; CAMPBELL, C. A.; LEYSHON, A. J.; NICHOLAICHUK, W. Boron toxicity and deficiency: A review. Canadian Journal Soil Science. Ottawa, v. 65, p. 381-409, 1985.

HODECKER, B. E. R.; NAIRAM, B.; IVO, S.; VALDIR, D.; JORGE, S.; MARCELO, L. Boron delays dehydration and stimulates root growth in Eucalyptus urophylla (Blake, S.T.) under osmotic stress. Plant and Soil, Perth, v. 384, p. 185199, 2014.

LIMA, S. F.; CUNHA, R. L.; CARVALHO, J. G.; ALBERTO, C.; SOUZA, A.; CORREA, F. L. O. Comportamento do paricá (Schizolobium amazonicum herb.) submetido à aplicação de doses de boro. Cerne, Lavras-MG, v. 9, n. 2, p. 192-204, 2003.

MALAVOLTA, E. Elementos de nutrição mineral. Piracicaba-SP: Ceres, 1980. 254 p.

MATTIELLO, E. M.; RUIZ, H. A.; SILVA, I. V.; SARKIS, J. E. S.; NEVES, J. C. L.; PUCCI, M. M. Phloem mobility of boron in two eucalypt clones. Revista Brasileira de Ciência do Solo, Viçosa-MG, v. 33, n. 06, p. 1695-1704, 2009a.

MATTIELLO, E. RUIZII, H. A.; SILVA, I. R.; SARKIS, J. E. S.; NEVES, J. C. L; PUCCI, M. M. Características fisiológicas e crescimento de clones de eucalipto em resposta ao boro. Revista Árvore, Viçosa-MG, v. 33, n. 5, p. 821-830, $2009 b$.

OKSANEN, J.; F. BLANCHET, G.; FRIENDLY, M.; KINDT, R.; LEGENDRE, P.; MCGLINN, D.; PETER R. M.; O'HARA, R. B.; GAVIN, L. S.; PETER, S. M.; STEVENS, H. H.; SZOECS, E.; WAGNER, H. Vegan: community ecology package. R package version 2.4-0. Available at, Oulu, p. 140142, 2016.2 Disponível em: $<$ https://CRAN.Rproject.org/package=vegan $>$. Acesso em: 15 mar. 2017.

OLIVEIRA, S. A.; BLANCO, S. A.; ENGLEMAN, M.; Influência do boro nos parâmetros morfológicos e fisiológicos de crescimento do feijoeiro. Pesquisa Agropecuária Brasileira, Brasília-DF, v. 17, n. 5, p. 683-688, 1982.

O'NEILL, M. A.; ISHII, T.; ALBERSHEIM, P.; DARVILL, A. G. Rhamnogalacturonan II: structure and function of a borate cross-linked cell wall pectic polysaccharide. Annual Review of Plant Biology, Califórnia, v. 55, n. 4, p. 109-39, 2004.

PEREZ, B. A. P.; VALERI, S. V.; CRUZ, M. C. P.; VASCONCELOS, R. T.; Potassium doses for African mahogany plants grow thunder two hydric conditions. African Journal of Agricultural Research, Joanesburgo, v. 11, n. 22, p. 1973-1979, 2016.

PINHEIRO A. L.; COUTO, L.; PINHEIRO, D. T.; BRUNETTA, J. M. F. Ecologia, silvicultura e tecnologia de utilização dos mognos-africanos (Khaya spp.). 1. ed. Viçosa-MG: Sociedade Brasileira de Agrossilvicultura, 2011. $102 \mathrm{p}$.

R DEVELOPMENT CORE TEAM. R version 3.2.0: A Language and Environment for Statistical Computing. Vienna, Austria: R Foundation for Statistical Computing. 2015. Disponível em: <http://www.R-project.org.>. Acesso: em 15 mar. 2017.

REIS, B. E.; PAIVA, H. N ; BARROS, T. C. ; FERREIRA, A. L. ; CARDOSO, W. C. Crescimento e qualidade de mudas de jacarandá-da-bahia (Dalbergia nigra (Vell.) Allemão ex Benth.) em resposta à adubação com potássio e enxofre, Ciência Florestal, Santa Maria-RS, v. 22, n. 2, p. 389-396, 2012.

RYAN, G. M.; STAPE, J. L.; BINKLEY, D.; FONSECA, S.; LOOS, A. R.; TAKAHASHI, E. N.; SILVA, C. R.; SILVA, S. R.; HAKAMADA, R. E.; FERREIRA, J. M.; LIMA, A. M. N.; GAVA, J. L.; LEITE, F. P.; ANDRADE, H. B.; ALVES, J. M.; SILVA, G. C. Factors controlling Eucalyptus productivity: how water availability and stand structure alter production and carbon allocation. Forest Ecology Management, Amsterdam, v. 259, n. 9, p. 1695-1703, 2010.

SIEBENEICHLER, S. C.; MONNERAT, P. H.; CARVALHO, A. J. C.; SILVA, J. A.; MARTINS, A. O. Mobilidade do boro em plantas de abacaxi. Revista Brasileira de Fruticultura, Jaboticabal-SP, v. 27, n. 2, p. 292-294, 2005.

SMIDERLE, O. J.; SOUZA, A. das G.; CHAGAS, E. A.; SOUZA, M. A.; FAGUNDES, P. R. O. Growth and nutritional status and quality of Khaya senegalensis seedlings. Revista Ciências Agrarias, Pernambuco-RE, v. 59, n. 1, p. 47-53, 2016.

TIRLONI, C.; DANIEL, O.; VITORINO, A. C. T.; NOVELINO, J. O.; CARDUCCI, C. E.; HEID, D. M.; Crescimento de Corymbia citriodora sob aplicação de boro nas épocas secas e chuvosas no Mato Grosso do Sul, Brasil. Silva Lusitana, Lisboa, v. 19 n. 2, p. 197-206, 2011 